\title{
Causes of Maternal Mortality According to Reports of Maternal Death Audits in the University Teaching Hospital Bogodogo (UTH-B) from January to December 2017
}

\author{
Ouattara Adama1,2*, Ouédraogo Smaila1,2, Lankoandé Bako Coulibaly Natacha ${ }^{3}$, \\ Kain Dantola Paul ${ }^{1,2}$, Tougma Sanou Aline ${ }^{3}$, Ouédraogo Marie Charlemagne ${ }^{1,2}$, \\ Ouédraogo Ali1,2, Thieba Bonané Blandine ${ }^{1,2}$
}

\begin{abstract}
${ }^{1}$ Training and Research Unit in Health Sciences (TRU/HS), University Ouaga 1 Pr Joseph KI ZERBO, Ouagadougou, Burkina Faso ${ }^{2}$ Department of Gynecology and Obstetrics, The University Teaching Hospital Yalgado Ouedraogo of Ouagadougou (UTH-YO), Ouagadougou, Burkina Faso

${ }^{3}$ Department of Gynecology and Obstetrics, The Bogodogo University Teaching Hospital of Ouagadougou (UTH-B), Ouagadougou, Burkina Faso

Email: *ouattzangaadama@yahoo.fr
\end{abstract}

\begin{abstract}
How to cite this paper: Adama, O., Smaila, O., Natacha, L.B.C., Paul, K.D., Aline, T.S., Charlemagne, O.M., Ali, O. and Blandine, T.B. (2018) Causes of Maternal Mortality According to Reports of Maternal Death Audits in the University Teaching Hospital Bogodogo (UTH-B) from January to December 2017. Open Journal of Obstetrics and Gynecology, 8, 1345-1353. https://doi.org/10.4236/ojog.2018.813136
\end{abstract}

Received: October 6, 2018

Accepted: November 9, 2018

Published: November 12, 2018

Copyright (c) 2018 by authors and Scientific Research Publishing Inc. This work is licensed under the Creative Commons Attribution International License (CC BY 4.0).

http://creativecommons.org/licenses/by/4.0/

\section{c) (i) Open Access}

\begin{abstract}
Objective: To study causes of maternal mortality according to reports of maternal death audits in the University Teaching Hospital Bogodogo (UTH-B) of Ouagadougou, Burkina Faso. Materials and Method: This was a prospective study that took place over a year from 1 January to 31 December 2017. It concerned maternal deaths that occurred during this period in the obstetrics and gynecology department of the University Teaching Hospital Bogodogo (UTH-B). All maternal deaths were systematically audited by the audit committee; interviews with providers and families were sometimes conducted. The record books of all patients were analyzed by the audit committee; if necessary, interviews were conducted with care providers and families. The main information collected were recorded on individual files, entered and analyzed using the software Epi-info 7. Result: During the study period, we recorded 32 maternal deaths i.e., 587 per 100,000 live births. Deceased women under age 20 were the most numerous, followed by women aged 20 to 24 . The death occurred in most cases in the puerperium in $69.80 \%$ of cases. Complications of pregnancy were the most incriminated causes in maternal deaths. Bleeding was the leading cause, accounting for $34.3 \%$. They are followed by hypertensive disorders of pregnancy $(21.8 \%)$ and infections $(18.8 \%)$. In the contributing factors, resource factors were incriminated in $56.2 \%$ of cases, social factors in $43.7 \%$ of cases and medical factors in $25.4 \%$ of cases.
\end{abstract}


Death was non-preventable in $76.2 \%$ of cases compared to $23.8 \%$ of preventable deaths. Conclusion: Maternal mortality is a major public health problem at the maternity hospital of the university hospital Yalgado Ouedraogo. Hemorrhage is the first cause of death. Hypertensive diseases are more and more worrying. Solutions must be found to improve the practice of audits in the obstetrics and gynecology department of UTH-B.

\section{Keywords}

Audits, Review, Maternal Deaths, Causes of Maternal Deaths

\section{Introduction}

Awareness of the quality of care as a determinant in the reduction of maternal mortality leads to a process of critical and systematic analysis of the quality of medical care by comparing procedures or services with reference to quality standards, in order to make corrections [1]. Burkina Faso, a west African developing country, had made considerable progress in combating maternal mortality and the maternal mortality ratio decreased from 566 per 100,000 live births in 1993 to 484 per 100,000 in 1998 and 341 per 100,000 in 2010 [2]. The known causes of maternal death are dominated by bleeding, dystocia, infections and complications of arterial hypertension [3]. These causes of death often reflect a lack of obstetric supervision and care, thus calling into question the quality of patient management in health facilities. In addition to the medical cause of maternal death, the audit highlights all the contributing factors that contributed to the death. It is knowledge of these factors that will enable relevant recommendations to be made at the end of the audit to resolve the relevant and priority problems identified. In the University Teaching Hospital Bogodogo (UTH-B), and more specifically at the maternity ward, there is already a team in charge of recording maternal deaths and organising audit sessions. Thus, we felt it necessary to conduct this study to report the experience of our obstetrical team on maternal death audits.

\section{Patients and Method}

It was a retrospective study that focused on women who died in the obstetrical gynecology department of the University Teaching Hospital Bogodogo (UTH-B) of Ouagadougou, Burkina Faso. It had been held over a period of one year from January 1, 2017 to December 31, 2017. Included were all women admitted alive to the UTH-B maternity ward who died during the study period and who met the World Health Organization (WHO) definition of maternal death. According to WHO, maternal death is defined as "the death of a woman during pregnancy or within 42 days of its termination, regardless of its duration and location, for any cause determined or aggravated by pregnancy or the care it caused, but neither accidental nor adventitious" [1]. The medical records of deceased patients 
were the primary sources of information. These files were analysed by the audit committee; where necessary, interviews were held with service providers and families. All deaths were systematically analysed by the audit committee; interviews with providers and families were sometimes conducted. It should be noted that the audit of each case usually begins with the staff or questions are asked to understand the case and at the same time challenge all actors to redouble their efforts to ensure optimal care offered to patients. Some of the cases audited were presented in plenary sessions and resulted in recommendations. At each restitution session, each recommendation is entrusted to an agent who is responsible for it. This person is responsible for implementing the recommendation in question. Four (4) restitution sessions were conducted and resulted in recommendations. We got the approval of the Ethics Committee on Research. The main information collected was recorded on individual sheets, entered and analysed using the Epi-info 7 software.

\section{Results}

\subsection{Mortality Ratio}

During the study period, we recorded 32 maternal deaths i.e., 587 per 100,000 live births (LB).

\subsection{Age Distribution of Patients}

Figure 1 below shows the age distribution of women. The average age is 26.57 years with extremes of 17 and 47 years.

\subsection{Distribution of Patients According to the Number of Anterior Childbirth}

The distribution of patients according to the number of anterior childbirth is shown in Figure 2.

\subsection{Period of Death}

Death occurred during pregnancy in $69.80 \%$ of cases (Figure 3 ).

\subsection{Distribution of Direct and Indirect Causes of Maternal Death}

Death was related to a direct cause in $73 \%$ of cases. Indirect causes accounted for $27 \%$. The distribution of deaths by cause is shown in Table 1 .

\subsection{Contributing Factors to Deaths}

\subsubsection{Medical Factors}

Table 2 shows the distribution of medical factors contributing to death.

Delay at referral and incorrect treatments were encountered in $12.7 \%$ and $6.3 \%$ respectively.

\subsubsection{Resource-Related Factors}

Table 3 shows the distribution of factors related to resources contributing to death. 
frequency (\%)

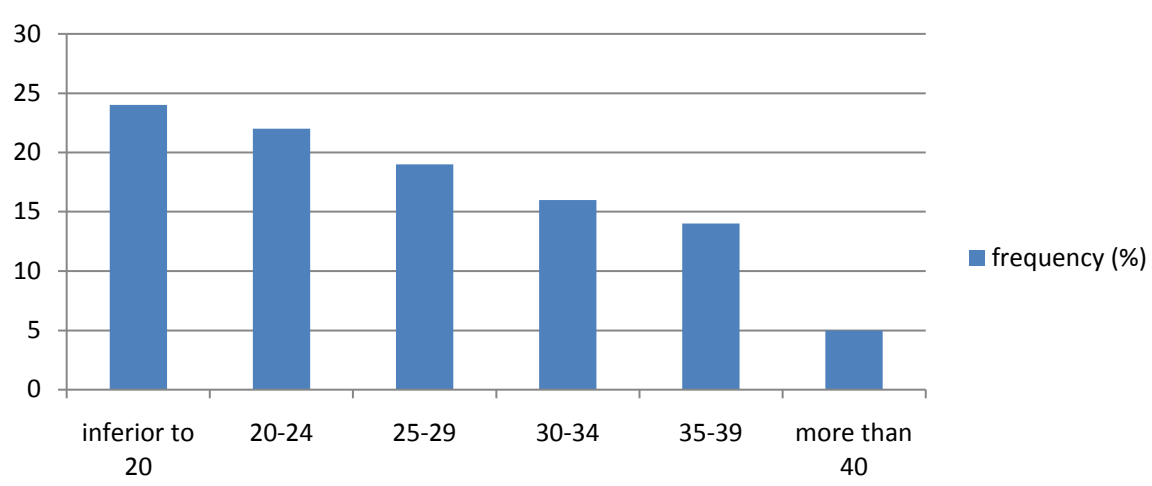

Figure 1. Women age distribution.

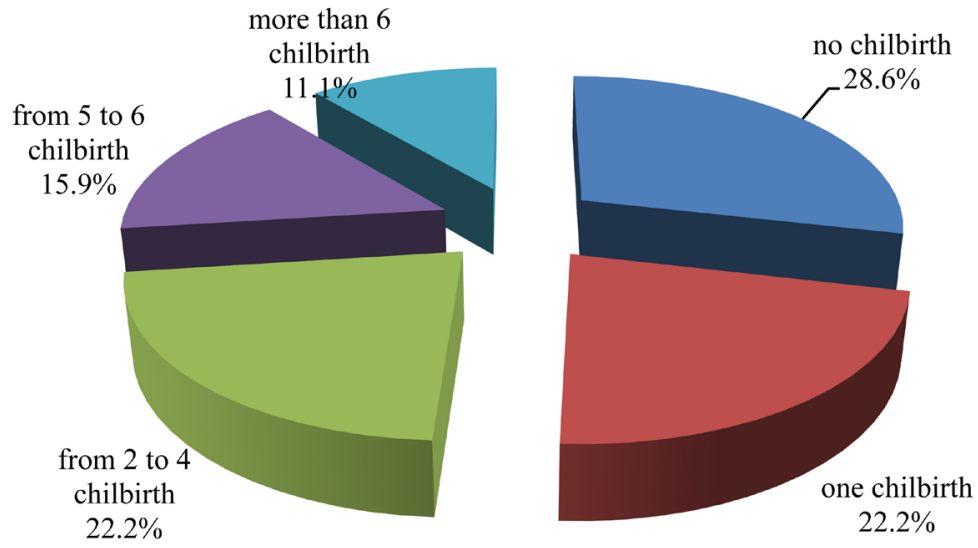

Figure 2. Distribution of deceased according to the number of anterior childbirth.

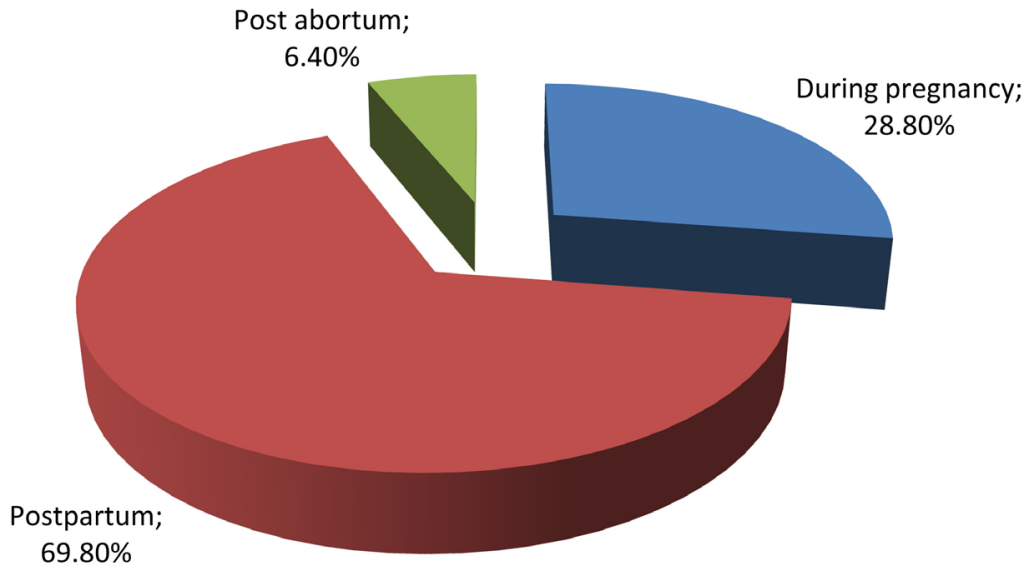

Figure 3. Distribution of deceased women according to the period of death during pregnancy.

Among the contributing factors related to resources, the lack of SLP and the lack of essential drugs were $28.6 \%$ and $15.9 \%$ respectively.

\subsubsection{Social Factors}

Table 4 shows the distribution of the social factors contributing to deaths. 
Table 1. Distribution of causes of death.

\begin{tabular}{lcc}
\hline Cause of death & Frequency & Percentage \\
\hline 1-Direct Causes & 11 & \\
$\checkmark$ Hemorrhages & 1 & \\
- Placenta Abruption & 4 & 34.3 \\
- Tear Soft Tissue & 4 & \\
- Hemorrhage of Delivery & 1 & \\
- Placenta Previa & 1 & \\
- Uterine Rupture & 7 & 21.8 \\
$\checkmark$ Pre eclampsia/Eclampsia & 6 & 18.8 \\
$\checkmark$ Infections & & \\
2-Indirect Causes & 04 & 12.5 \\
$\checkmark$ Chronic Anemia & 01 & 3.1 \\
$\checkmark$ Cardiopathy & 01 & 3.1 \\
$\checkmark$ Anesthesia Complication & 02 & 6.4 \\
$\checkmark$ Malaria & 32 & 100 \\
\hline Total & &
\end{tabular}

Table 2. Distribution of medical factors.

\begin{tabular}{ccc}
\hline Medical Factors & Number & Percentage \\
\hline Delay at Referral & 4 & 12.7 \\
Incorrect Treatment & 2 & 6.3 \\
Protocol Not Followed & 1 & 3.2 \\
Diagnostic Delay & 1 & 3.2 \\
Diagnostic Mistake & 1 & 3.2 \\
\hline
\end{tabular}

Table 3. Distribution of resource factors.

\begin{tabular}{ccc}
\hline Resource-related factors & Number & Percentage \\
\hline Lack of PSL (Labile Blood Products) & 9 & 28.1 \\
Lack of essential drug & 5 & 15.6 \\
Non-functional operating jar & 2 & 6.3 \\
Lack of a blood pressure monitor & 1 & 3.2 \\
Oxygen Rupture & 1 & 3.2 \\
\hline
\end{tabular}

Table 4. Distribution of social factors.

\begin{tabular}{ccc}
\hline Social factors & Number & Percentage \\
\hline Delay in consultation & 6 & 18.7 \\
Ignorance & 3 & 9.4 \\
Traditional treatment & 2 & 6.2 \\
Lack of financial means & 1 & 3.1 \\
Home delivery & 1 & 3.1 \\
\hline
\end{tabular}


Late consultation and ignorance accounted for $20.6 \%$ and $8 \%$ respectively.

\section{Discussion}

\subsection{Epidemiological Aspects}

The mortality ratio in our study was 587 per 100,000 LB. It is clearly lower than that reported during a study in the same centre in 2012 [4].

The average age was 26 years in our study. This average age is comparable to that reported by OUEDRAOGO [4], ALIHONOU and collaborator [5] in their series. The 20 to 34 age group was the most represented at $57.1 \%$ with extremes ranging from 17 to 47 years. This could easily be explained by the fact that this is the age group where reproductive activity is most intense in women. Our data are similar to those of TRAORE M in Mali [6] which reported 54.7\% for the 20 to 34 age group with extremes of 17 and 47. DUMONT and collaborators [7] in Senegal reported in 2006 in Senegal a predominance of the 17 to 34 age group. Nulliparous women were the most represented in our study, at $28.6 \%$. We find this explanation in the fact that young women were the most represented in our study. MBONGO BE and collaborators [8] in Brazzaville in Congo reported in their study in 2008 a predominance of primiparous women. Death occurred postpartum in $69.8 \%$ of cases. Indeed, post-natal periods are also dangerous and require special attention from health workers and families. Unfortunately, the high workload and sometimes the negligence of health workers and families mean that vigilance decreases once women give birth, thus explaining the high number of deaths in the postpartum period. Our figures are comparable to those of TRAORE in Mali, which reported 59.5\% postpartum deaths in its series.

\subsection{The Causes of Maternal Death}

The causes of death are dominated by haemorrhages in (33.3\%), followed by hypertensive disorders of pregnancy with (28.8\%) and infections (17.5\%). Bleeding in most African series is the leading cause of death [3] [4] [9]. They may reflect the significant dysfunction in the care provided by health services and the lack of SLPs. BOUVIER Colle M-H and colleagues [10] in France reported bleeding as the leading cause of death in 2004. Hypertensive pregnancy disorders ranked second in our series. This classification is comparable to that of BA M-G [11] in Senegal which classified eclampsia as the second cause of death in its series. In the OUEDRAOGO C and BOUVIER-Colle M-H [3] series, the second cause of death is contested by infection and eclampsia. Causes of death due to pregnancy complications accounted for $73.0 \%$ in our study. PRUAL [12] of the AQUASOU project reported in 2004 in its publication $79 \%$ of direct medical causes of maternal deaths in developing countries SAIZENOU [13] and collaborators in Benin reported in 2006 in their series 74\% of direct causes of maternal deaths. The direct causes of death would reflect the quality of follow-up during pregnancy and childbirth. They therefore call on all actors to make greater efforts in the care of pregnant women. 


\subsection{Contributing Factors}

Medical factors that contributed to deaths, delay at referral, incorrect treatments were the most observed. Patients evacuated to UTH-B sometimes arrive in a very critical state, complicating their care. Although most of the referrals were made by ambulance, most of them were not medicalized despite their critical condition at the time of evacuation. The plenary sessions to present the audits or all the health actors of the city of Ouagadougou were invited to solve even this dysfunction linked to the references. As highlighted by PRUAL A. [12], and TOURE B. [14] in Côte d'Ivoire, the role of providers is considerable in the occurrence of maternal mortality. This was also noted by RICHARD F. and colleagues [15] who mentioned the lack of enforcement of agents in their series. Factors related to resources, lack or insufficiency in SLP were noted several times (28.6\%) of the cases. This same observation was made by SAIZENOUS J. and collaborators [13] in their 2006 series in Benin.

The lack of essential medicines $(15.9 \%)$ is a factor limiting the rapid response of health services. Prescriptions given to parents for urgent cases will take several minutes or even hours to be filled due to the long queue at UTH-B's pharmaceutical depot. Also the incompleteness of emergency kits is a significant contributing factor. Of the contributing social factors, the delay in consultation was noted as in $20.6 \%$ of cases. This social factor was also reported by ALIHONOU and collaborator [5] in Benin in their study on escapement audits. Indeed, some patients consulted for the first time at a very advanced stage of the disease, as evidenced by the short delay between admission and death and the significant alteration of their condition at admission. This social phenomenon could be explained partly by ignorance, the lack of financial resources of the populations and partly by the loss of public confidence in health services. The use of traditional products $(6.3 \%)$, home deliveries $(4.8 \%)$ unassisted (4.8\%) are social factors nowadays that negatively influence the health of the population. Audits with population interviews are the only opportunities for health workers to assess the perception of health services by the population. In this context, audits will enable health services to be adapted to the needs of the population so that these services can be harmoniously integrated into their social environment. GUNAWAN S. [16] in Indonesia reported delay in consultation as the primary contributing factor to maternal deaths.

\section{Conclusion}

Maternal mortality is a major public health problem at the maternity hospital of the university hospital Bogodogo. Hemorrhage is the first cause of death. Hypertensive diseases are more and more worrying. Initiatives need to be taken to address this problem, which hampers the capture of the demographic dividend.

\section{Conflicts of Interest}

The authors declare no conflicts of interest regarding the publication of this paper. 


\section{References}

[1] WHO (2004) Beyond Numbers. Examine Maternal Deaths and Complications to Reduce Pregnancy-Related Risks. WHO, Geneva, 150 p.

[2] INSD (2012) Demographic, Health and Multiple Indicator Survey (EDSBF-MICS IV) 2010. INSD, Ouagadougou, $501 \mathrm{p}$.

[3] Ouedraogo, C. and Bouvier, M.H. (2002) Maternal Mortality in West Africa: How, How Many and Why? Journal de Gynécologie Obstétrique et Biologie de la Reproduction, 31, 42-46. http://www.em-consulte.com/recherche/resultats

[4] Ouedraogo, C., Testa, J. and Sondo, B. (2001) Analysis of Risk Factors for severe Maternal Morbidity in Ouagadougou, Burkina Faso: Application to the Prenatal Record. Médecine d'Afrique Noire, 48, 403-410.

[5] Alihonou, E. (2000) Maternal Mortality in Sub-Saharan Africa. OMAS Journal, 1, 24-32.

[6] Traore, M., Mounkoro, N. and Malle, C.K. (2008) Audit of Maternal Deaths at the Reference Health Centre of Commune v of the District of Bamako: About 42 Cases. Master Thesis, University of Bamako, Bamako.

[7] Dumont, A., Dompnier, J.-P. and Bouvier Colle, M.-H. (2002) Maternal Morbidity and Qualification of Health Personnel: Comparison of Two Different Populations in Senegal. Journal de Gynécologie Obstétrique et Biologie de la Reproduction, 31, 70-79.

[8] Mbongo, B.E., Mbemba, G.M., Mokoko, J.C., Gombet Koulimaya, C.E., Mbongo, J.A., Koubaka, R. and, Iloki, L.H. (2012) Clinical Audit of Maternal Deaths at the University Hospital of Brazzaville. SAGO, 63-67.

http://sago.sante.gov.ml/index.php?:congres-sago-bamako-2008

[9] Ouedraogo, C., Ouédraogo, A., Ouattara, T., Akotionga, M., Thiéba, B. and Lankoandé, J. (2001) La mortalité maternelle au Burkina Faso: Evolution et stratégie nationale de lutte. Black African Medicine, 48, 452-456.

http://www.santetropicale.com/Resume/114802.pdf

[10] Bourvier Colle, M.-H., Deneux, C., Szego, E., Cornet, C., Michel, E., Varnoux, N. and Janglo, E. (2004) Mise au point sur la mortalité maternelle en France: Fréquences, tendances et causes. Journal de Gynécologie Obstétrique et Biologie de la Reproduction, 30, 768-775.

[11] Ba, M.-G., Kodio, B. and Etard, J.-F. (2003) Application of Verbal Autopsy in the Measurement of Maternal Mortality in Rural Senegal. Journal de Gynécologie Obstétrique et Biologie de la Reproduction, 32, 23-28.

https://www.ncbi.nlm.nih.gov/pubmed/15067897

[12] Prual, A. (2004) Reducing Maternal Mortality in Developing Countries: Theory and Practice. Médecine Tropicale, 64, 569-575. https://www.ncbi.nlm.nih.gov/pubmed/15816133

[13] Saizonou, J., De Brouwere, V. and Vangeenderhuysen, C. (2006) Audit of the Quality of the Care of the "Near Misses" in the Maternity Homes of Reference in Southern Benin. Health, 16, 33-42.

[14] Touré, B. (2005) Identification of Dysfunctions in the Management of Severe Maternal Morbidity in Abidjan. CAIRN INFO, 17, 135-144. http://www.cairn.info/revue-sante-publique-2005-1-page-135.htm

[15] Richard, F., Oue'draogo, C., Zongo, V., Ouattara, F., Zongo, S., Grue'nais, M. and De Brouwere, V. (2009) The Difficulty of Questioning Clinical Practice: Experience of Facility-Based Case Reviews in Ouagadougou, Burkina Faso. BJOG, 116, 38-44. 
https://doi.org/10.1111/j.1471-0528.2008.01741.x

[16] Gunawan, S., Meg, E.W., Endang, A., Surekha, C. and Ronsmans, C. (2002) A District-Based Audit of the Causes and Circumstances of Maternal Deaths in South Kalimantan, Indonesia. Bulletin of the World Health Organization, 80, 228-234.

http://www.who.int/fr 